\title{
Changing views of emotion regulation and neurobiological models of the mechanism of action of psychotherapy
}

\author{
Irene Messina ${ }^{1,2} \cdot$ Marco Sambin $^{2} \cdot$ Petra Beschoner $^{3} \cdot$ Roberto Viviani $^{4,1}$
}

Published online: 28 June 2016

(C) Psychonomic Society, Inc. 2016

\begin{abstract}
Influential neurobiological models of the mechanism of action of psychotherapy attribute its success to increases of activity in prefrontal areas and decreases in limbic areas, interpreted as the successful and adaptive recruitment of controlled processes to achieve emotion regulation. In this article, we review the behavioral and neuroscientific evidence in support of this model and its applicability to explain the mechanism of action of psychotherapy. Neuroimaging studies of explicit emotion regulation, evidence on the neurobiological substrates of implicit emotion regulation, and metaanalyses of neuroimaging studies of the effect of psychotherapy consistently suggest that areas implicated in coding semantic representations play an important role in emotion regulation not covered by existing models based on controlled processes. We discuss the findings that implicate these same areas in supporting working memory, in encoding preferences and the prospective outcome of actions taken in rewarding or aversive contingencies, and show how these functions may be integrated into process models of emotion regulation that depend on elaborate semantic representations for their effectiveness. These alternative models also appear to be more
\end{abstract}

Irene Messina

Irene-messina@hotmail.com

1 Department of Psychiatry and Psychotherapy III, University of Ulm, Ulm, Germany

2 Department of Philosophy, Sociology, Education and Applied Psychology (FISSPA), University of Padua, Via Belzoni 84, 35121 Padua, Italy

3 Department of Psychosomatic Medicine and Psychotherapy, University of Ulm, Ulm, Germany

4 Institute of Psychology, University of Innsbruck, Innsbruck, Austria consistent with internal accounts in the psychotherapeutic literature of how psychotherapy works.

Keywords Emotion regulation $\cdot$ Semantics $\cdot$ Psychotherapy · Neuroimaging $\cdot$ Avoidance $\cdot$ Suppression

The efficacy of psychotherapy has been demonstrated by several empirical studies (for meta-analyses of psychotherapy outcome studies, see Leichsenring \& Rabung, 2011; Lipsey \& Wilson, 1993; Smith \& Glass, 1977; Westen \& Morrison, 2001). However, the exact mechanisms through which psychotherapy acts are not well understood. An influential model of the mechanism of action of psychotherapy draws on data from the considerable number of studies that have applied clinical neuroscience approaches (primarily functional neuroimaging) to identify the brain-behavior circuits that change during therapy (for reviews, see Abbass, Nowoweiski, Bernier, Tarzwell, \& Beutel, 2014; Beauregard, 2007; DeRubeis, Siegle, \& Hollon, 2008; Disner, Beevers, Haigh, \& Beck, 2011; Frewen, Dozois, \& Lanius, 2008; Messina, Sambin, Palmieri, \& Viviani, 2013). According to this model, psychotherapy may act by promoting the effectiveness of control processes of executive nature, whose neurobiological substrate may be located in prefrontal areas (see Fig. 1, in green), representing successful activation of emotion regulation strategies in the face of exposure to emotionally salient stimuli, especially when these stimuli possess anxiogenic or other emotionally negative features (Beauregard, 2007; DeRubeis et al., 2008; Disner et al., 2011; Frewen et al., 2008; Messina et al., 2013). We place this model within the framework of a general class of theories about mental function, which we will refer to as the dual-process framework (Barrett, Tugade, \& Engle, 2004). 


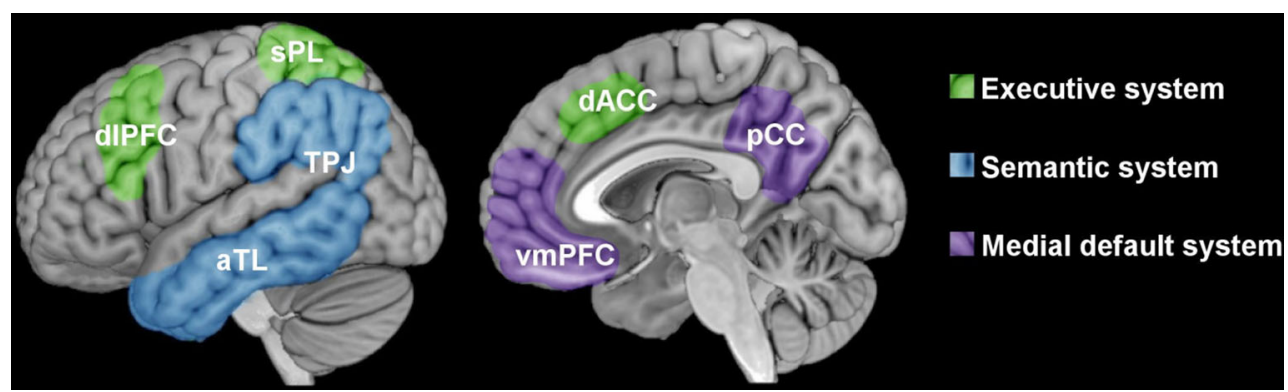

Fig. 1 Graphical representation of neural systems involved in models of emotion regulation and psychotherapy. In green are areas commonly associated to executive function (retrieved from http://neurosynth.org/; Yarkoni, Poldrack, Nichols, Van Essen, \& Wager, 2011). In blue are association areas that have been shown to be activated by semantic

The dual-process model of psychotherapy has its origins in neuroimaging investigations describing emotion regulation as a complex mechanism that simultaneously involves cognitive and emotional component processes whose neural correlates are located in a prefrontal-limbic network. More specifically, these studies have described the involvement of dorsolateral prefrontal cortex (dlPFC) and dorsal anterior cingulate (dACC), cortical areas that are part of the voluntary attentional system and are associated to the recruitment of executive control processes (Corbetta, Patel, \& Shulman, 2008; Duncan \& Owen, 2000; Hopfinger, Buonocore, \& Mangun, 2000; Owen, McMillan, Laird, \& Bullmore, 2005; see Fig. 1, in green) in tasks in which the influence of emotional distracters had to be kept at bay or in tasks in which explicit instructions to regulate one's reaction to emotional stimuli was given (Banich et al., 2009; Beauregard, Levesque, \& Bourgouin, 2001; Compton, 2003; Compton et al., 2003; Kalisch, Wiech, Herrmann, \& Dolan, 2006; Luo et al., 2007; Ochsner, Bunge, Gross, \& Gabrieli, 2002; Phan et al., 2005; Whalen et al., 1998). For this reason, activation of these areas may be interpreted as evidence for the recruitment of a regulatory function of executive nature in emotion-regulation tasks (Banich et al., 2009; Drevets \& Raichle, 1998; Ochsner \& Gross, 2005). Within this framework, the hallmark of adaptive emotion regulation is characterized as the effective recruitment of cognitive control processes of executive nature, in contrast to the processes that are responsible for the generation of the emotional reaction, which may run largely without requiring costly and limited cognitive resources (Bishop, Duncan, Brett, \& Lawrence, 2004a; Phillips, Drevets, Rauch, \& Lane, 2003; Siegle, Thompson, Carter, Steinhauer, $\&$ Thase, 2007). Hence, the core idea of these models is that psychotherapy acts by improving the efficacy of control processes in inhibiting emotional reactivity (DeRubeis et al., 2008; Disner et al., 2011; Posner et al., 2003).

Because of the amount of empirical evidence gathered in its favor and the unquestionable relevance of executive processes in mechanisms of emotion regulation, it seems appropriate to ask how far the dual-process model has come in meeting its tasks in neuroimaging studies (Binder et al., 2009). In lilac are areas in the medial aspect of the brain that are also activated by semantic tasks (Binder et al., 2009) and are considered to be part of the set of cortical areas that may become active during rest (Raichle et al., 2001). (Color figure online)

goals of clarifying what mechanisms underlie change in psychotherapy. Here, our purpose is to review empirical evidence on a number of key issues that, in our view, are important to assess the construct of emotion regulation as a factor of psychotherapeutic change. First, we will address the question of the existence of nonadaptive forms of emotion regulation that appear to rely on control processes of executive nature. To this end, we will identify examples from the clinic or present behavioral and neuroimaging evidence suggesting that cognitive control per se is not specific to adaptive regulation. Second, we will review recent behavioral and neuroimaging evidence on implicit or spontaneous emotion regulation. This evidence suggests that implicit forms of regulation may not involve executive function, being associated with the modulation of a network of brain areas that are part of a semantic system storing lifetime information to encode, identify, and interpret external stimuli, and that are involved in the recognition of stimuli of motivational relevance (see Fig. 1, in blue and violet). These findings raise questions about whether these forms of regulation can be accommodated within the processes dichotomy of the dual-process framework. Third, we will assess the extent to which empirical evidence from functional neuroimaging studies matches the predictions based on the dualprocess model on the neural substrates of emotion processing and control involved in psychotherapy change. These data provide considerable evidence that is consistent with the dual-process model, but also present important inconsistencies. Specifically, the available evidence from studies of psychotherapy change suggests the involvement of the same ventral network of areas that have been associated with semantic or emotional processes.

In the final part of the article, we will discuss the role this ventral network may play in models of change associated with therapy. Those who are familiar with the stated aims of a wide range of psychotherapy approaches may, perhaps, not be surprised by the suggestion of the importance of semantic processes for understanding their mechanisms of action. However, precisely because the meaning of experience and of interpersonal interactions is discussed with patients in 
psychotherapy, the involvement of semantic processes may be a nonspecific finding. The question that needs to be addressed is how interventions on semantic processes may result in apparent changes in the capacity to regulate emotion. To address this issue, we will briefly review findings in systems neuroscience that appear to us to be important to capture the full effect of changes in semantic processing on motivation and control, and that if considered may enrich our understanding of what psychotherapy does. We will present data suggesting that areas in the inferior parietal, temporal, and ventral prefrontal cortex, which host semantic association processes or are concerned with representing stimuli with emotional valence, should be considered in future attempts to model change in therapy.

\section{Dual-process models of emotion regulation and psychotherapy}

Dual-process models describe behavior on the basis of two different and in many ways opposed processes, most often corresponding to the distinction between the controlled and the automatic (Barrett et al., 2004). Controlled processes are endogenous and involve top-down attentional mechanisms and voluntary attention. When qualified, as in the expression "cognitive control," these processes refer to any form of control that presents the features of executive function, such as being based on limited resources or being subject to interference. In contrast, automatic processes are originated by exogenous sensorial inputs that steer attention through bottom-up attentional mechanisms and are carried out without requiring apparent effort from the individual. At the neural level, this distinction corresponds to the involvement of prefrontal areas, whose activation decreases gradually when the task becomes automatic - for example, through extensive practice (Logan, 1988; Raichle et al., 1994).

The dual-process model has been proposed as a framework to explain emotion regulation, the process through which individuals modulate their emotions to respond to environmental demands appropriately (Aldao, Nolen-Hoeksema, \& Schweizer, 2010; Gross, 1998). Emotion regulation is considered a critical factor in models of development and maintenance of psychopathology (Aldao \& Nolen-Hoeksema, 2010; Berking \& Wupperman, 2012) and an important aim of psychological interventions (Berking et al., 2008; Greenberg \& Pascual-Leone, 2006). Most neuroimaging studies of emotion regulation have used emotional visual stimuli (Lang \& Bradley, 2007) to compare brain activity during an "attend condition" and during a "regulate condition." In the attend condition, participants were instructed to respond naturally to stimuli, whereas in the regulate condition they were instructed to use emotion regulation strategies in which they had been previously trained (Ochsner \& Gross, 2005). As it has emerged from meta-analyses of these studies (Buhle et al., 2014; Diekhof, Geier, Falkai, \& Gruber, 2011; Kohn et al., 2014), the neural substrates of emotion regulation are located in a prefrontal-limbic network (see Fig. 2), which includes several prefrontal areas-dorsolateral prefrontal cortex (dIPFC), dorsal anterior cingulate (dACC), and ventrolateral prefrontal cortex (vlPFC) - which inhibit subcortical areas associated to emotional reactivity, such as the amygdala (Wager, Davidson, Hughes, Lindquist, \& Ochsner, 2008). These results have been interpreted as a major involvement of controlled processes in responding to emotional stimuli, instead of letting relatively automatic reactions take their course and determine response (Ochsner \& Gross, 2008).

The dual-process model has found application in interpretations of the cerebral functional changes observed as an effect of psychotherapy in neuroimaging investigations. Studies that compared the brain signals obtained before and after treatment have reported changes that are consistent with this model of emotion regulation in depression (Buchheim et al., 2012; Dichter, Felder, \& Smoski, 2010; Goldapple et al., 2004), phobic disorders (Almeida et al., 2013; Schienle, Schafer, Hermann, Rohrmann, \& Vaitl, 2007; Straube, Glauer, Dilger, Mentzel, \& Miltner, 2006), panic disorder (Beutel, Stark, Pan, Silbersweig, \& Dietrich, 2010; Sakai et al., 2006), posttraumatic stress disorder (Lindauer et al., 2008; Thomaes et al., 2014), personality disorders (Schnell \& Herpertz, 2007), and eating disorders (Vocks et al.,2010; Vocks et al., 2011). In the treatment of depression, these studies have provided evidence that the neural correlate of psychotherapy may consist in increased activation of prefrontal areas when participants are exposed to emotional stimuli, representing successful recruitment of control processes in the context of emotion regulation (DeRubeis et al., 2008; Disner et al., 2011). An analogous model has been proposed for anxiety disorders (Bishop, Duncan, Brett, \& Lawrence, 2004b; Etkin \& Wager, 2007), where the involvement of prefrontal areas after psychotherapy has been viewed as evidence for the recruitment of controlled processes in the generation of the response to emotional stimuli (see also Bishop et al., 2004a; Bishop, Jenkins, \& Lawrence, 2007; Kalisch, Wiech, Critchley, \& Dolan, 2006). These models have been proposed to interpret the neural correlates of change not only in different disorders but also across different psychotherapy approaches, such as behavioral therapy (Hauner, Mineka, Voss, \& Paller, 2012; Paquette et al., 2003), cognitive therapy (Fu et al., 2008; Goldapple et al., 2004; Kennedy et al., 2007), and psychodynamic therapy (Beutel et al., 2010; Buchheim et al., 2012). We characterize all these models as instances of a dualprocess model because they all have in common the idea that psychotherapy acts through the improvement of the 


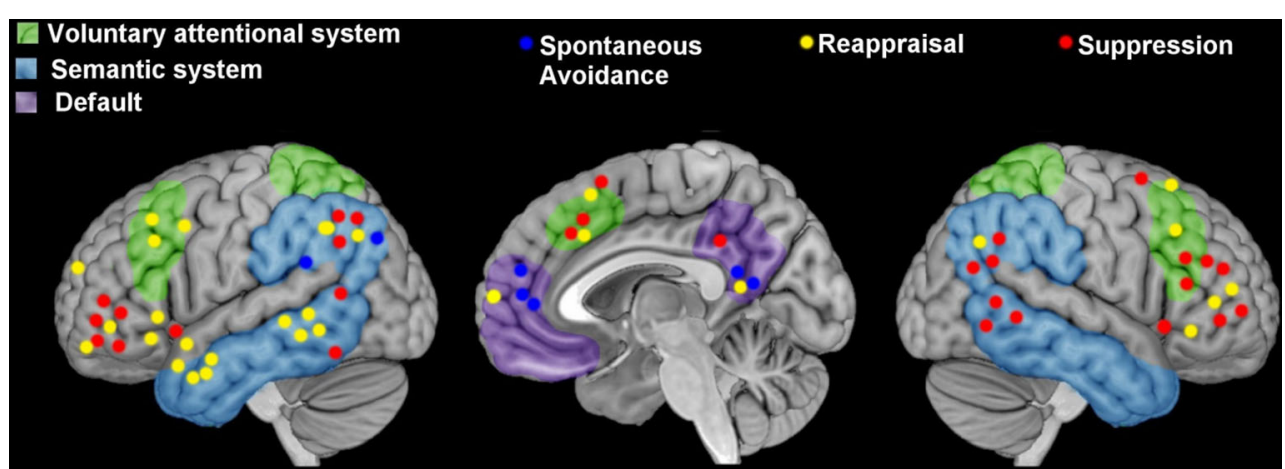

Fig. 2 Neural correlates of emotion regulation. Neural correlates of reappraisal (yellow circles) and suppression (red circles) previously reported in three studies that have compared reappraisal and suppression (Goldin et al., 2008; Hayes et al., 2010; Vanderhasselt

efficacy of control processes to inhibit emotional reactivity.

\section{Maladaptive consequences of cognitive control}

In the dual-process model of emotion regulation, top-down cognitive control of emotion is viewed as having a positive adaptive value. However, cognitive control of emotions may not always have positive consequences for psychological well-being. One source of evidence on the existence of dysfunctional aspects of cognitive control is given by a series of studies that have investigated its paradoxical effects (Dalgleish, Yiend, Schweizer, \& Dunn, 2009; Rude, Durham-Fowler, Baum, Rooney, \& Maestas, 2010; Rude, Valdez, Odom, \& Ebrahimi, 2003; Rude, Wenzlaff, Gibbs, Vane, \& Whitney, 2002; Wenzlaff, Rude, Taylor, Stultz, \& Sweatt, 2001; Wenzlaff \& Rude, 2002; Wenzlaff \& Wegner, 2000). These studies have been interpreted as evidence for the notion that attempts to voluntarily suppress mental content may have the paradoxical effect of increasing its accessibility to consciousness. This "rebound effect" may be explained by the ironic effect theory, which postulates the existence of two processes acting in parallel during the voluntary suppression of mental content: on the one hand, a voluntary process that promotes suppression; on the other hand, a monitoring process that acts in the background, without requiring extensive cognitive resources, with the aim to detect failures of the first process (Wegner, 1994). Due to the monitoring process, the mental content to be suppressed and its associated nodes remain to some extent active, promoting strengthening of the associative links. This makes their suppression by the voluntary process ineffective in the long term. Examples of paradoxical effects of cognitive control are evident in several aspects of psychopathology: rumination of negative unwanted thoughts is a common symptom in depression (Beevers \& Meyer, 2004; Grimm et al., 2011; Wegner, Erber, \& Zanakos, 1993; Wenzlaff, Wegner, \& Roper, 1988) and in et al., 2012). Neural correlates of spontaneous avoidance (blue circles) previously reported in studies of intrinsic emotion regulation (Benelli et al., 2012; Viviani et al., 2010). (Color figure online)

mixed anxiety and depressive symptoms (Nolen-Hoeksema, 2000); the intrusion of traumatic memories together with their avoidance is a symptom of posttraumatic stress disorders (Shipherd \& Beck, 2005); and paradoxical effects may also be a component of obsessive-compulsive disorder (for a review and meta-analysis, see Abramowitz, Tolin, \& Street, 2001).

Another source of evidence for the existence of both positive and negative consequences of cognitive control are studies showing that different emotion regulation strategies vary in adaptive value. One of the most adaptive strategies of emotion regulation is reappraisal, consisting of the generation of new interpretations of stressful situations to decrease the emotional response they would otherwise elicit (Gross, 1999). Empirical evidence suggests the existence of an association between the use of reappraisal and increased expression of positive emotion, increased interpersonal functioning, and increased wellbeing when compared to other forms of regulation, such as behavioral suppression (Gross, 2002; Gross \& John, 2003). Moreover, reappraisal has been shown to be positively associated with mental health, and negatively with emotional disorders (Aldao et al., 2010; Hu et al., 2014; Joormann \& Gotlib, 2010). Among the relatively less adaptive emotion regulation strategies, suppression is one of the most investigated. Compared to reappraisal, suppression has been negatively associated to the expression of positive emotion, effective interpersonal functioning, and well-being (Gross, 2002; Gross \& John, 2003). Moreover, suppression is negatively correlated with mental health indicators (Hu et al., 2014), and its habitual use has been observed in patients with depression and anxiety diagnoses (Aldao \& Nolen-Hoeksema, 2010).

Emotion regulation through reappraisal has been investigated in many functional neuroimaging studies, which showed the involvement of prefrontal areas (including structural changes; Falquez et al., 2014; Giuliani, Drabant, \& Gross, 2011) and the down-regulation of limbic structures such as the amygdala (Buhle et al., 2014; Diekhof et al., 
2011; Kohn et al., 2014). At the neural level, however, the dual-process model of emotion regulation does not explain the differences between adaptive and maladaptive forms of emotion regulation. Although the majority of neuroimaging studies have evaluated reappraisal, in some cases also suppression (Goldin, McRae, Ramel, \& Gross, 2008; Ohira et al., 2006; Phan et al., 2005), distraction (McRae et al., 2010), and distancing (Koenigsberg et al., 2010) have been investigated. As shown in Fig. 2, foci of brain activation in suppression and reappraisal involve similar components of the prefrontal network associated with cognitive control (Goldin et al., 2008; Hayes et al., 2010; Vanderhasselt, Baeken, Van Schuerbeek, Luypaert, \& De Raedt, 2012). Some authors have suggested that different emotion regulation strategies could be distinguished by the degree of cognitive control, reflecting less recruitment of cognitive strategies in suppression compared to reappraisal (Vrticka, Sander, \& Vuilleumier, 2011). Others have presented evidence suggesting that differences between reappraisal and suppression may be explained by considering the existence of different temporal dynamics in neural responses, accounting for an earlier modulation of emotional responses in reappraisal compared to suppression (Goldin et al., 2008; Kalisch, 2009).

In all of these accounts, however, it is not the recruitment of executive control processes per se that characterizes adaptive forms of emotion regulation, but rather the extent or the timing of this recruitment. Consistent with this notion, a study in which reappraisal was compared with avoidance of emotional stimuli by focusing on a demanding cognitive task found very similar prefrontal regions recruited in both cases (Kanske, Heissler, Schonfelder, Bongers, \& Wessa, 2011). Other studies suggest that the same regulatory areas are recruited in depression, without, however, leading to the desired beneficial effect (Johnstone, van Reekum, Urry, Kalin, \& Davidson, 2007). Similarly, it has been suggested that inhibition of negative content may be viewed as a shared process in both reappraisal and rumination (Cohen, Daches, Mor, \& Henik, 2014). Furthermore, teaching more adaptive attention-focusing strategies as a therapeutic intervention does not seem to affect recruitment of prefrontal areas (Goldin et al., 2013).

Interestingly, some psychotherapy approaches explicitly address the use of attentional resources, such as in the case of mind-body therapies (meditation, hypnosis, yoga, EMDR therapy). An example is mindfulness-based therapy (Segal, Williams, \& Teasdale, 2012), in which patients are instructed to observe negative thoughts using a mindfulness attitude consisting in "paying attention on purpose, in the present moment, and non-judgmentally to the unfolding of experience moment by moment" (Kabat-Zinn, 2003, p. 145). This therapy approach emphasizes the use of attentional processes to promote acceptance, nonjudgment, and nonreaction to thoughts, feelings, and sensations in contrast with the idea of the high adaptive value of inhibition as postulated by the dual-process model.

In summary, although it is certainly desirable to be able to resort to executive function for control, it does not seem that use of executive function per se or recruitment of the neural substrates associated with executive function differentiate between more and less adaptive forms of control. Although confirming the importance of cognitive control for emotion regulation, behavioral studies on negative consequences of cognitive control and neuroimaging investigations that describe the involvement of the same prefrontal-subcortical circuits in both adaptive and maladaptive forms of emotion regulation raise questions about its role as a key mechanism of psychotherapy change. It seems that recruitment of executive control alone (or activation of its neural substrates) is not sufficient to conclude for the adaptive value of the strategy of emotion regulation followed by participants. Rather, although an efficient executive may surely be viewed as a desirable trait, it also appears that other aspects of mental function, perhaps influencing how and to what control is applied, should be considered when the aim is to characterize emotion regulation as adaptive or maladaptive.

\section{Implicit emotion regulation}

Emotion regulation has been characterized as a process through which individuals modulate their emotion explicitly or implicitly (Gross, 1999). Explicit emotion regulation refers to conscious efforts to regulate emotion, suggesting recruitment of cognitive control processes. Reappraisal, which we described in the previous section, belongs to this type of emotion regulation strategy. Implicit emotion regulation, in contrast, has been defined as "any process that operates without the need for conscious supervision or explicit intentions, and which is aimed at modifying the quality, intensity, or duration of an emotional response" (Koole \& Rothermund, 2011, p. 401). To date, empirical and theoretical efforts have been mainly directed to forms of regulation in which conscious efforts play a central role, whereas the investigation of implicit emotion regulation has remained elusive.

Mauss, Bunge, and Gross (2007) refer to "automatic emotion regulation" to describe implicit forms of regulation that are widely used in specific social contexts to decrease emotional responses. For example, an individual may regulate his or her emotions automatically, in compliance with implicit social norms, or as a habit learned early in childhood (for example, "men do not cry" or "anger is dangerous"). Such forms of regulation are defined as "automatic" due to the absence of voluntary intention, but at the same time they are considered goal-directed. In this case, the use of the term automatic reflects the attempt to remain inside a dual- 
process model of regulation (Gyurak, Gross, \& Etkin, 2011). However, the concept of automaticity is also commonly related to efficiency, uncontrollability, and exogenous attentional focus. None of these features play any role in the definition of implicit regulation (Koole \& Coenen, 2007). Ultimately, it is not clear whether the concept of implicit emotion regulation is compatible with the dual-process model described above. Rather, it seems that this concept implies a process with characteristics that are intermediate between the controlled and the automatic, given its goal-directedness in the absence of conscious efforts.

Note that the emotion regulation literature contains several studies in which regulation follows from explicit instructions and is qualified as automatic, a word usage that does not correspond to the notion of implicit emotion regulation we are considering here. This is the case, for example, when emotional distracters are used in tasks in which the task instruction does not explicitly refer to the emotional nature of the stimuli to be controlled (for review, see Viviani, 2013). Although the encoding of the emotional quality of these stimuli may occur automatically or even outside of awareness, the process that is responsible for this encoding is not the process that may be responsible for control. Tasks that explicitly attempt to ignore distracters direct cognitive control processes to suppressing these stimuli, even if their emotional nature is not mentioned in the instructions to participants. In contrast, an operational definition of implicit emotion regulation would require that the task be successfully executed even if the emotional material enters working memory, or that the instruction be completely neutral with respect of whether emotional material should influence the response. A tendency to ignore bad news, for example, may be present even if the bad content is per se more salient and the task is to select a piece of news arbitrarily to repeat later. The question is, is this kind of regulation mediated by the same processes of executive nature that can produce emotion regulation in explicit tasks.

A long-standing clinical tradition has emphasized the importance of forms of regulation that cannot be ascribed to executive function. In psychodynamic approaches, for example, the notion of defense mechanisms refers to processes that act by modifying and distorting thoughts, feelings, and wishes whose recognition would create excessive anxiety (Freud, 1926). In line with this definition, defense mechanisms can be seen as implicit forms of emotion regulation because they are not intentional, but at the same time they are directed to avoiding anxiety generated by intrapsychic conflict, to protecting from breakdown of self-esteem, or to promoting self-integration (Cramer, 1999).

In cognitive-behavioral therapy, distortions of thoughts, feelings, and wishes are described as the effect of dysfunctional (implicit or explicit) schemas. These schemas may at times determine behavior outside the awareness of the individual and in a fairly automatic fashion (James, Southam, \&
Blackburn, 2004; McGinn \& Young, 1996). Although in cognitive-behavioral therapy implicit schemas are not viewed as defenses against deeper unsettling drives as in the psychoanalytic tradition, they do organize the individual's appraisal of negative contingencies by framing them within negative and painful experiences of the past. Furthermore, they in turn trigger maladaptive coping styles in an automatic or unconscious fashion. The coping style of schema avoidance, for example, consists of blocking thoughts and images related to the schema or of behavioral avoidance strategies (Young, Klosko, \& Weishaar, 2003). Several psychotherapy approaches that emphasize the role of cognition see schema activation as the mechanism to motivate behavior variously described as coping responses (Young et al., 2003), procedural sequences (Ryle, 1991), or defensive control processes (Horowitz, 1997).

Neuroimaging investigations on implicit forms of emotion regulation represent a challenge to researchers because of the impossibility of using an explicit instruction to regulate in experimental paradigms. To the best of our knowledge, only few studies in the literature have investigated spontaneous avoidance of emotional material using a functional neuroimaging approach (see Fig. 2, in blue). Viviani and colleagues (2010) have investigated spontaneous emotion regulation using a scrambled-sentence task that allows evaluating the spontaneous avoidance of negative cognitions in the healthy and inversely correlates with depressiveness and depression relapse (Rude et al., 2003; Wenzlaff, 1991). The scrambledsentences task consists in the presentation of a set of scrambled words from which participants can assemble sentences with pessimistic or optimistic connotations (e.g., the set "is bleak the future bright" may be reassembled into either "the future is bright" or "the future is bleak"). When the instruction is to form a sentence, without mention of which sentence should be chosen among the possible alternatives, healthy individuals only form about $20 \%$ to $30 \%$ negative sentences in this task. Comparing brain activations without and with an additional instruction to avoid the negative alternative, this study provided evidence of a dissociation between spontaneous and voluntary emotion regulation. Voluntary avoidance was associated with sustained activation of executive attentional areas (including dlPFC), whereas the same network was less recruited during spontaneous avoidance. This was part of a pattern of partial transfer of activations from dorsal to ventral areas (including the anterior inferior parietal and vmPFC). In a second study by Benelli and colleagues (2012), participants were exposed to emotional and neutral material (emotional vs. neutral narratives) during an fMRI scan. The participants were subsequently asked to write what they remembered from the material presented during the scan. The number of emotional words using by participants was used as a covariate indexing emotional avoidance (with less emotional words corresponding to more avoidance) to be correlated with the signal 
obtained while they were reading the narratives in the scanner. As in the study of Viviani and colleagues (2010), individual differences in emotional avoidance scores were shown to modulate brain areas that belonged to the ventral portion of the medial wall of the cerebral hemispheres, such as vmPFC and the posterior cingulus. These results suggest a dissociation of neural substrates recruited by explicit and implicit regulation that would be consistent with the theoretical distinction between these two forms of regulation.

\section{Importance of semantic representations in internal accounts of psychotherapy and the semantic system}

Although the dual-process model draws attention to the issue of the role of cognitive control in pathology and its possible adaptive use after therapy, internal accounts of prominent psychotherapy approaches transversally emphasize revision or "restructuring" of semantic representations as a key therapeutic factor. Here, we use the term semantic broadly to refer to attributes of representations that arise from generalizing regularities of experience in interaction with the world, an subsequently used to make sense of new encounters with the environment. This aspect of mental functioning has been investigated by several independent strands of psychological research, which have highlighted different but complementary aspects of it.

In clinical psychology, semantic representations play a key role in cognitive models of clinical conditions. Psychotherapy theories are often concerned with semantic representations of past experiences, current interpersonal situations, of self and others that function as schemas to organize and interpret the emotional significance of daily experience. Cognitive models of affective disorders, for example, emphasize the importance of cognitive vulnerability factors, in which appraisal of the environment and the self during experienced early adverse events are integrated into cognitive schemas (Beck, 1976, 2008). When activated, these schemas are responsible for the negative bias in interpreting reality and viewing the self during episodes of depression.

In the study of cognition, the notion of schema refers to the relatively automatic, involuntary, and resource-sparing encoding of information from the environment that relies on information stored in long-term memory to organize new material rapidly (Bobrow \& Norman, 1975; Rumelhart \& Ortony, 1977). In the study of memory, the term semantic refers to the fact that traces of experienced regularities are no longer explicitly linked to the episodes in which they were experienced. As in information-based models, here too the importance of semantic memory in encoding new experience and providing an inferential basis to interpret reality is emphasized (Tulving, 1972). The notion of semantic memory, as used in this strand of research, may be appropriate for embedding the notion of schema in a concrete model of psychic processes, because it explicitly refers to regularities of experience captured as informational referents ("cognitive referents of input signals"), rather than regularities at the mere perceptual level ("perceptible properties of inputs"), and makes explicit reference to its constructive nature (as in language) and its role in the capacity for generalization (Tulving, 1972).

The clinical notion of schema differs from its counterpart in the study of cognition in two important respects. The first is the emphasis on the encoding of interpersonal interactions, and the second is the motivational and affective consequences in activating specific schemas, including the generation of expectations about future events with a specific emotional tone. Hence, the clinical notion of schema assumes that the motivating and affect-eliciting properties of experience are stored in its schematic memory traces (Greenberg \& Pascual-Leone, 2006; Young, 1994).

Transversally to several psychotherapy approaches, much therapeutic work may be seen as encouraging awareness and critical revision of schematic appraisals of reality in interpersonal interactions, supporting the more competent schemas among those available from the individual repertories, or developing more adaptive schemas and creating supraordinate self-schemas to integrate contradictory schematic features (Horowitz, 1994). For example, classical cognitive approaches are based on the modification of affect-inducing thoughts and schemas that arise or are deployed automatically (Beck, Rush, Shaw, \& Emery, 1979), or of semantic representations corresponding to "irrational" beliefs (Ellis, 1989). In schema-focused therapy, schema revision is accompanied by empathic confrontation and limited parenting to address the emotional consequences of the tendency to activate specific schemas (Young et al., 2003). More recent approaches have extended the scope of cognitive therapy by promoting the construction of semantic representations of meta-emotions and metacognitions (Wells, 2011). Similarly, interpretation, the core technique of psychoanalysis, implies the revision of the meaning assigned to appraisals or actions (Etchegoyen, 2005). Hence, mental representations of cognitive-affective schemas appear to be a central constituent of emotional disorders and psychotherapy models in several approaches.

Given the importance that the revision of schemas has in several psychotherapy approaches, it seems justified to pay attention to the issue of the neurobiological substrates of semantic representations. Moving from the analysis of deficits from brain lesions (Hodges \& Patterson, 1995; Mesulam, 1998; Tranel, Damasio, \& Damasio, 1997), functional neuroimaging studies have uncovered the involvement of a much larger system of cortical areas than those traditionally classified as "association cortex" (Patterson, Nestor, \& Rogers, 2007). This system includes the inferior parietal lobe, the temporo-parietal junction (TPJ), and the anterior/middle 
temporal lobes (aTL) (Binder, Desai, Graves, \& Conant, 2009; Jefferies, 2013; Patterson et al., 2007; Visser, Jefferies, $\&$ Ralph, 2010; see Fig. 1, in blue). In addition, areas that were not traditionally associated with semantic memory are also consistently activated in functional neuroimaging studies, including the vmPFC and the posterior cingulus (Binder et al., 2009; Fairhall \& Caramazza, 2013; see Fig. 1, in violet). Within these neural substrates, medial prefrontal areas and the inferior parietal lobe have been specifically associated in functional neuroimaging studies to emotional semantic representations in tasks involving stimuli of expressed emotion (Grimm et al., 2009; Lindquist, Wager, Kober, BlissMoreau, \& Barrett, 2012; Peelen, Atkinson, \& Vuilleumier, 2010). The TPJ and aTL have also been associated with tasks of "social cognition" and the appraisal of expressive body posture (Amodio \& Frith, 2006; De Gelder, 2006; Saxe, 2006). The neuroimaging data on the extension of the traditional notion of semantic memory to the encoding of emotional and interpersonal situations converge with those obtained in recent studies on the consequences of brain lesions in aTL, showing impairments in retrieving representations of relationships that govern social interactions (Irish, Hodges, \& Piguet, 2014; Zahn et al., 2007) and representations of the self (Lou et al., 2004; Sperduti et al., 2013). These findings are consistent with the emphasis on the emotional and interpersonal aspects of experience of the clinical notion of schema.

The inclusion of areas such as the ventromedial/ orbitofrontal cortex and the anterior insula among the substrates of semantic memory is consistent with the notion that regularities of experience are stored in association areas. The hallmark of these areas, in comparison with those in the parietal and temporal lobes more traditionally associated with semantic storage, may be the affective relevance of the stored information. Whereas parietal and temporal association cortices surround visual, auditory, and somatosensory areas, the ventromedial/orbitofrontal cortex and the anterior insula are adjacent to primary olfactory and gustatory areas (Rolls, 2000). Neurophysiological studies in laboratory animals and functional imaging in humans show that associative memory to rewarding or aversive experiences are stored in these areas (Balleine, Leung, \& Ostlund, 2011; Gottfried \& Zelano, 2011; Howard, Gottfried, Tobler, \& Kahnt, 2015; Liljeholm, Tricomi, O’Doherty, \& Balleine, 2011; Noonan, Kolling, Walton, \& Rushworth, 2012; Parkes, Bradfield, \& Balleine, 2015; Rudebeck, Saunders, Prescott, Chau, \& Murray, 2013; Schoenbaum, Roesch, Stalnaker, \& Takahashi, 2009).

A specific contribution of functional neuroimaging to our understanding of this cortical system is the distinction between cortical areas that are active when processing external information that presents sensory regularities but is essentially devoid of semantic content, such as pseudowords (Binder, Medler, Desai, Conant, \& Liebenthal, 2005) and when facing tasks that require access to semantic information, including information of affective nature (Binder et al., 2009). Following a terminology used in functional neuroimaging studies, we will refer to this network of areas as the "semantic system," and to the associated processes dedicated to encoding the meaning of experience as "semantic processes."

\section{The neural correlates of psychotherapy and emotion regulation}

Several functional neuroimaging studies have investigated the neural substrates of change in psychotherapy treatment, including cognitive approaches. The question that we would like to address is whether these studies provide any evidence on adaptive or maladaptive uses of cognitive control, or of the involvement of the semantic system, in the changes induced by psychotherapy.

Because these studies have been often conducted with cognitive control tasks, consistently with the dual-process model described above, they represent a test bed of the implicit hypothesis that changes promoted by psychotherapy facilitate explicit emotion regulation through the effective recruitment of cognitive control (Disner et al., 2011). The key prediction of this hypothesis concerns the involvement of dorsal prefrontal areas associated with executive function. This hypothesis is supported by several studies on the effects of psychotherapy in which the involvement of prefrontal areas has been reported (for reviews, see Frewen et al., 2008; Messina et al., 2013; see also Fig. 3). In most studies, changes following psychotherapy have been detected when considering task-related activations (Beutel et al., 2010; Fu et al., 2008). In these studies, the prefrontal cortex has been found to be more active after psychotherapy, a finding that is consistent with an increase of cognitive control in response to environmental exposure to emotional stimuli.

However, studies of activity of the brain at rest have reported effects on prefrontal cortex activity, which has been observed to decrease after psychotherapy (Goldapple et al., 2004; Kennedy et al., 2007). If correct, these findings suggest that prefrontal activity cannot be unconditionally interpreted as adaptive. Rather, in line with the studies of maladaptive forms of cognitive control, these results may be interpreted as a reduction of dysfunctional control, such as rumination concerning negative thoughts or memories and processing of irrelevant information (Goldapple et al., 2004; Taylor \& Liberzon, 2007). Taken together, such results are consistent with the notion of an improvement in the capacity to use specific forms of cognitive control and the decrease in the use of nonadaptive forms of cognitive control as an effect of psychotherapy. However, this implies that the adaptive value of the use of cognitive control depends on the modality of its use rather than on the recruitment of cognitive control per se. 


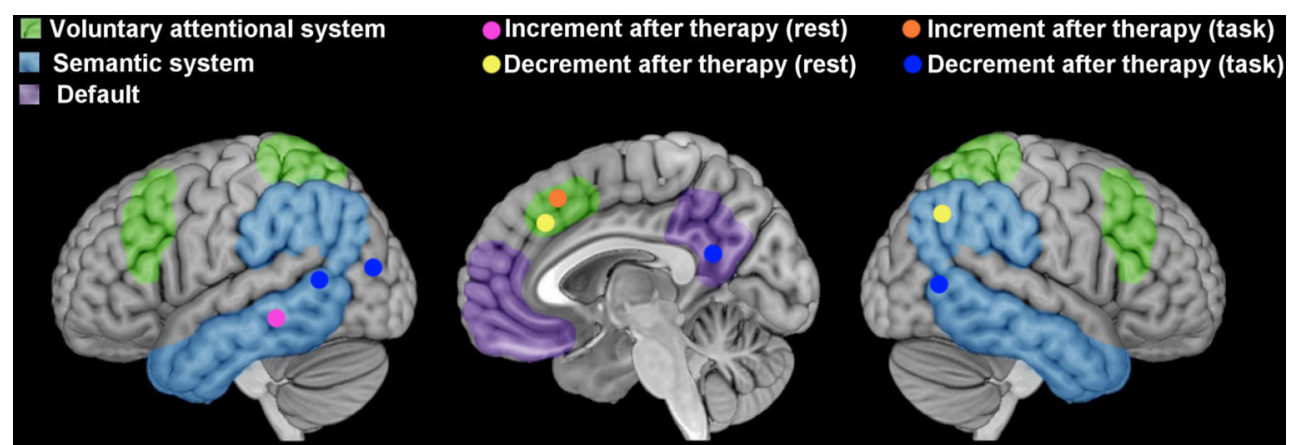

Fig. 3 Neural effects of psychotherapy. Clusters of brain activity changes after psychotherapy in executive areas (in green) and semantic areas (in blue), based on a meta-analysis of functional neuroimaging studies of the effects of psychotherapy (Messina et al., 2013). (Color figure online)

An issue that naturally arises concerns the existence of effects in areas belonging to the semantic system, consistently with the notion, common in internal accounts of its practice, that psychotherapy work targets meaning associated with or leading to emotional reactions. Meta-analyses of neuroimaging studies of the effect of psychotherapy show that significant changes may occur in the temporal cortex, a key node of the semantic system (Messina et al., 2013; see Fig. 3). This finding is perhaps all the more remarkable because it emerges from a data-driven analysis of the data, instead of being driven by prior hypotheses in the original studies.

It is also worth noting that meta-analyses and formal reviews of emotion regulation studies have shown the existence of activations in the semantic system (Buhle et al., 2014; Diekhof et al., 2011; Kohn et al., 2014; Viviani, 2013). As it is apparent from Fig. 2, tasks of explicit emotion regulation recruit not only the dorsal prefrontal areas that are typically associated with executive function, but also the temporal and parietal lobes (Messina, Bianco, Sambin, \& Viviani, 2015). These findings, which are not predicted by dual-process models of emotion regulation, suggest the involvement of areas of the semantic system in effortful regulation.

In summary, despite the fact that the findings of prefrontal and limbic activity changes in neuroimaging studies of psychotherapy are consistent with the dual-process model, empirical evidence suggests the involvement of processes that go beyond the prefrontal-limbic dynamic. In particular, both considerations from the theory of the clinical process and the neuroimaging data reviewed here are consistent with the notion that changes in semantic representations may constitute an essential aspect of psychotherapeutic interventions and at least some forms of emotion regulation.

\section{The possible role of semantic processes in emotion regulation and mechanisms of psychotherapy change}

Neurobiological models that have been formulated within the cognitive approach to psychotherapy do not disavow the semantic nature of the psychotherapeutic intervention; rather, they posit that this intervention may lead to improvements in the recruitment of cognitive control in emotion regulation, thus explaining clinical improvement (Disner et al., 2011). Following the dual-process framework outlined above, these models locate cognitive control processes in the prefrontal lobes, a choice justified by the wealth of evidence on the association of these areas with executive processes, and of their role in reining in activation in structures like the amygdala when exposed to emotionally salient stimuli (Banich et al., 2009; Compton, 2003; Hariri, Bookheimer, \& Mazziotta, 2000; Hofmann, Schmeichel, \& Baddeley, 2012; Ochsner \& Gross, 2005; Pessoa, McKenna, Gutierrez, \& Ungerleider, 2002; Posner \& Rothbart, 2007). However, the evidence we have reviewed suggests that activation of prefrontal areas per se is not necessarily adaptive. Furthermore, it is not clear why schema restructuring may lead to increased cognitive control, especially given that simply paying attention to emotionally laden content is not necessarily beneficial, as studies of rumination suggest. Because of the emphasis on the direct effect of executive control, these accounts are not concerned with the existence of mechanisms through which changes in semantic processing may underpin the increased efficiency of control in emotion regulation as when selectively processing positive, instead of negative, environmental stimuli.

The findings of activations in the semantic system in the functional neuroimaging studies we have reviewed do not, per se, show how changes in representations may affect emotion regulation. However, their significance may change when viewed in the context of a wider set of findings that address the role of the semantic system within a process model that clarifies its role in cognitive control and thereby helps us to understand how changes in semantic representations might affect emotion regulation. Within this wider context, we believe that two (not necessarily incompatible) models should be considered.

One model builds on the biased competition theory of working memory (Desimone \& Duncan, 1995), originally 
formulated without reference to emotion processing. According to this model, executive processes achieve control by biasing the competition between representations of incoming stimuli for accessing working memory. Similarly, cognitive accounts of working memory increasingly assume its action to be exerted through a dynamic allocation of attention that changes the state of activation of representations in longterm memory (Cowan, 1988; McElree, 1998; Oberauer, 2009). These accounts are supported by evidence from functional neuroimaging studies which show that neural signatures of items held in working memory can be retrieved from the BOLD signal of semantic areas (D'Esposito \& Postle, 2015). Because in this view working memory is to some extent a state in which representations are put, performance of cognitive control cannot be considered as completely independent from performance of semantic storage in long-term memory. If representations include complex semantic encodings of stimuli or more general contingencies, such as those arising from interpersonal interactions and the self, then it is reasonable to assume the existence of individual variations about the content of semantic repertoires based on past experience. This is because, although the experience of "chairs" may be common enough to give rise to representations with similar characteristics in individuals of the same culture, representations of regularities of interpersonal interactions will be much more under the influence of one's personal and social history, as the psychotherapeutic notion of schema suggests. However, if cognitive control acts by biasing or configuring the activation of representations, then one's representations must have an effect on how executive control can make its influence felt. Hence, in addition to the variation in cognitive control capacities, individual differences in emotion regulation may ensue from the organization of semantic representations. For example, poor semantic representations of interpersonal interactions may result in rigid and exaggerated emotional responses, or their suppression, because in the absence of semantic nodes coding a rich repertoire of interpersonal interactions, appraisal of these interactions will more likely be reduced to the perception of their mere appetitiveness or aversiveness. Hence, when the semantic repertoire of the individual is lacking, all one can do is face the naked emotional consequences of interpersonal adversity directly, without the mediation of a cognitive representation of the circumstances in which this adversity occurred and why. This may lead to a specific form of emotionally driven functioning, which psychotherapy approaches characterize with varying terminology, but that usually refers to a structural deficit whose treatment requires special techniques.

In cognitive reappraisal, there is evidence for a deeper engagement of semantic processes than of emotion regulation strategies such as suppression, as revealed by higher recall rates in episodic memory tasks (Hayes et al., 2010). Because of its reliance on semantic processes, it is conceivable that the capacity to think about alternative contexts for the emotional episode requested by cognitive reappraisal may be facilitated by the availability of multiple, more varied representations (Barrett, Gross, Christensen, \& Benvenuto, 2001; Cole, Michel, \& Teti, 1994; Thompson, 1994). These findings are consistent with the state-based view of working memory and may explain the conspicuous recruitment of areas in the semantic system, such as the inferior parietal and temporal areas, in neuroimaging studies of reappraisal. Studies of cognitive control in affective disorders that propose the existence of a deficit at the interface between control and activation of semantic nodes may also be consistent with this model (Joormann \& Gotlib, 2010; Joormann, Levens, \& Gotlib, 2011). The level of organization of semantic representations may also be important to model those therapeutic interventions that appear to aim at creating more complex representations of interpersonal interactions than patients originally had (Bateman \& Fonagy, 2004), thus providing new opportunities for fine-grained control. In contrast to typical cognitive approaches, the aim of these interventions is not the refutation of the patient's original appraisal of interpersonal situations (which may be contraindicated in some patients), but coaching patients to apply a wider range of potential interpretations of the possible internal motives of others in the interaction, instead of viewing them simply as good or bad. Several early neuroimaging studies showed that changing the focus of semantic encoding of standard emotionally arousing stimuli toward abstract linguistic labeling led to a reduction of the activation of the amygdala (Hariri et al., 2000; Lieberman et al., 2007). A similar mechanism may operate in the semantic encoding of personal interactions, where the availability of labels is much more variable across individuals.

A more radical departure from the dual-process framework considers the possibility that parts of the semantic system may exert a form of control of their own, distinct from the control stemming from executive processes. This possibility was first discovered in the study of patients with orbitofrontal lesions, which show impulsivity traits and impairments in decision making without concomitant deficits in executive function (Bechara, 2004; Bechara, Damasio, Tranel, \& Anderson, 1998). In this model, executive function is not, in principle, required for control. Several studies have suggested that ventral parts of the medial cerebral wall, such as vmPFC and the posterior cingulated gyrus ( $\mathrm{pCC}$ ), which are part of the wider system of areas identified by studies of the semantic system (Binder et al., 2009; see Fig. 1, in lilac) may be involved in regulating emotional responses. These findings have led to the suggestion that these areas may have a regulatory function specifically directed to emotional content (for reviews, see Etkin, Egner, \& Kalisch, 2011; Viviani, 2014). However, this regulatory process does not seem to be of an executive nature. Indeed, vmPFC is deactivated by focused effortful tasks (Northoff et al., 2004; Shulman et al., 1997), and its activation 
has also been detected in the absence of cognitive control (Kosson et al., 2006).

A useful perspective on the function of these cortical regions is given by studies showing that in humans and nonhuman primates, vmPFC and the adjacent orbitofrontal cortex encode preferences and the prospective reward of actions taken in rewarding or aversive contingencies (for a review, see Rangel \& Clithero, 2013). This network may belong to the semantic system because it stores experience on the affective value of encountered stimuli and situations that determine personal preferences. It has been proposed that these areas compute a "value function" of stimuli or available alternative choices by integrating sensory representations in interaction with posterior association cortices in parietal and temporal areas, on the basis of which a preference is expressed (Gottfried \& Zelano, 2011; Kable \& Glimcher, 2009; Rangel, Camerer, \& Montague, 2008). An important aspect of these representations of subjective value is that they are not static, but are modulated by internal states reflecting the drives or needs of the individual (Small, Zatorre, Dagher, Evans, \& Jones-Gotman, 2001) and integrate complex information from affective memories of past states or experiences (Wilson, Takahashi, Schoenbaum, \& Niv, 2014).

Representations of subjective value in vmPFC and the adjacent areas may affect behavior by storing information about the outcome of choices when interacting with a limbic network intimately concerned with emotional functioning. Data from laboratory animals show that the information on the affective valence of stimuli is stored in vmPFC in interaction with the amygdala (Schoenbaum, Setlow, Saddoris, \& Gallagher, 2003; Seymour \& Dolan, 2008), a limbic structure that is essential to encode the appetitive or aversive valence of experience (Morrison \& Salzman, 2010; Murray, 2007). The close functional ties of the orbitofrontal and insular cortices with the limbic centers that supervise conditioning and Pavlovian responses, such as the amygdala, are consistent with models in the psychotherapeutic literature in which schema activation triggers "coping responses." In some of these accounts, coping responses are explicitly considered as elaborations of innate Pavlovian responses, such as fight or flight (Young et al., 2003).

The network that includes vmPFC and the adjacent orbitofrontal and insular cortices does not act alone in determining response, because cognitive control can override choices based on personal inclinations and preferences (Hare, Camerer, \& Rangel, 2009; McClure, Laibson, Loewenstein, \& Cohen, 2004). However, it does constitute a key node in a behavioral-neural circuit that integrates semantic encoding of external stimuli and internally stored motivational aspects of experience to form a separate controller of behavior (Bechara, Damasio, \& Damasio, 2000), thus explaining the forms of emotional impulsivity arising from damage to vmPFC. An example of the controlling role of vmPFC is given by the capacity to express preferences for long-term rewards, as opposed to short-term impulsive choices (Bechara, Damasio, Damasio, \& Anderson, 1994; Kable \& Glimcher, 2007). Another example is its involvement in extinction (Graham \& Milad, 2014; Milad \& Quirk, 2012; Phelps, Delgado, Nearing, \& LeDoux, 2004).

The functional neuroimaging studies of intrinsic emotion regulation reviewed previously have also reported the recruitment of the semantic system, including vmPFC, as part of a general shift of activation from the dorsal areas associated with executive control and attentional selection of external stimuli to ventral areas in the semantic system. This finding is consistent with a regulatory role of vmPFC. The analysis of the tasks in the functional neuroimaging literature activating the ventromedial/orbitofrontal cortex in terms of a process model suggests a form of effortless regulation, with characteristics that borrow from both the controlled and the automatic (Viviani, 2014), as would be appropriate for intrinsic regulation.

These considerations open new lines of inquiry for neural models of emotion regulation and the effects of psychotherapy. To investigate the relevance of state-based models of working memory, future studies may investigate the effects of control processes on the semantic network in tasks targeting the interference of emotional stimuli, as in proactive interference. Proactive interference consists of memory intrusions from information that was previously relevant to the task but has since become irrelevant, similarly to unwanted thought that occurs for some reason, which the thinker attempts to eliminate (Hasher, Lustig, \& Zacks, 2007; Postman \& Underwood, 1973). In tasks of proactive interference, the performance of semantic storage is put under stress, because it must be configured optimally to accommodate changing activations of representations under the direction of working memory. Among the possible components of executive functions, proactive interference has been hypothesized to be specifically associated with emotional disorders (Friedman \& Miyake, 2004). A second avenue of future research involves paradigms that elicit spontaneous or intrinsic forms of regulation, which have so far been neglected by research programs addressing the neurobiological substrates of emotion regulation. Although the study of spontaneous regulation is challenging due to the difficulty of standardizing empirical research, it may provide insights as to the integration of cognition and the emotional determinants of choice.

\section{Conclusions}

The aim of this review was to bridge an existent gap between neurobiological and clinical models of emotion regulation and psychotherapy by reviewing the evidence for the involvement of the neural substrates of executive 
and of semantic processes, and by formulating possible mechanisms through which modifications of semantic processes may bring about change that is not only adaptive but is also associated with better regulation. Despite their importance in internal accounts of what psychotherapy is about, semantic processes have been neglected in current neurobiological models of the mechanism of psychotherapy. Drawing on the dual-process framework, these models posit increased activation of prefrontal areas and decreased activation in limbic areas when participants are exposed to emotional stimuli, representing successful recruitment of control processes in the context of emotion regulation. However, the existing studies on brain changes after psychotherapy confirm the predictions of the dualprocess model only in part, reporting effects in areas of the semantic system. Furthermore, the possible existence of maladaptive forms of cognitive control and of implicit emotion regulation raises the issue of the importance of forms of emotion regulation that are less dependent on explicit executive processes. The neuroimaging of implicit emotion regulation suggests the involvement of parts of the semantic system, especially the ventromedial prefrontal cortex. Therefore, both theoretical considerations and findings in neuroimaging studies bring up the problem of assessing the contribution of changes in semantic processing in psychotherapy.

A key issue in modeling the action of psychotherapy is the mechanism through which work on semantic representations may bring about improvements in emotion regulation. We have reviewed findings in current systems neuroscience that provide potential models of how work on representations may improve emotion regulation, either by their restructuring or by favoring an adaptive recruitment of processes of executive nature. One of these models emerges from the analysis of how working memory functions by interacting with representations in longterm memory, drawing attention to the importance of interference between representations and capacity to resist them. A second model focuses on processes that have been so far investigated in the study of the neurobiology of choice and that are active in tasks requiring the evaluation of preferences or contingencies to achieve desired or aversive outcomes. This evaluation relies on representations of past experiences of the appetitiveness of aversiveness of outcomes. In both models, we suggest that mechanisms acting on the semantic system may better reflect the stated purpose of many psychotherapeutic techniques and interventions than the mechanism of directly strengthening executive function. Furthermore, research on the semantic system may open new prospects for the integration of our understanding of psychotherapy in an interdisciplinary context that includes neurobiological models of choice and emotional processing.

\section{References}

Abbass, A. A., Nowoweiski, S. J., Bernier, D., Tarzwell, R., \& Beutel, M. E. (2014). Review of psychodynamic psychotherapy neuroimaging studies. Psychotherapy and Psychosomatics, 83(3), 142-147.

Abramowitz, J. S., Tolin, D. F., \& Street, G. P. (2001). Paradoxical effects of thought suppression: A meta-analysis of controlled studies. Clinical Psychology Review, 21(5), 683-703.

Aldao, A., \& Nolen-Hoeksema, S. (2010). Specificity of cognitive emotion regulation strategies: A transdiagnostic examination. Behaviour Research and Therapy, 48(10), 974-983.

Aldao, A., Nolen-Hoeksema, S., \& Schweizer, S. (2010). Emotionregulation strategies across psychopathology: A meta-analytic review. Clinical Psychology Review, 30(2), 217-237.

Almeida, A. G., Araujo Filho, G. M. D., Berberian, A. D. A., Trezsniak, C., Nery-Fernandes, F., Araujo Neto, C. A., ... Oliveira, I. R. D. (2013). The impacts of cognitive-behavioral therapy on the treatment of phobic disorders measured by functional neuroimaging techniques: A systematic review. Revista Brasileira De Psiquiatria, 35(3), 279-283.

Amodio, D. M., \& Frith, C. D. (2006). Meeting of minds: The medial frontal cortex and social cognition. Nature Reviews Neuroscience, 7(4), 268-277.

Balleine, B. W., Leung, B. K., \& Ostlund, S. B. (2011). The orbitofrontal cortex, predicted value, and choice. Annals of the New York Academy of Sciences, 1239(1), 43-50.

Banich, M. T., Mackiewicz, K. L., Depue, B. E., Whitmer, A. J., Miller, G. A., \& Heller, W. (2009). Cognitive control mechanisms, emotion and memory: A neural perspective with implications for psychopathology. Neuroscience \& Biobehavioral Reviews, 33(5), 613-630.

Barrett, L. F., Gross, J., Christensen, T. C., \& Benvenuto, M. (2001). Knowing what you're feeling and knowing what to do about it: Mapping the relation between emotion differentiation and emotion regulation. Cognition \& Emotion, 15(6), 713-724.

Barrett, L. F., Tugade, M. M., \& Engle, R. W. (2004). Individual differences in working memory capacity and dual-process theories of the mind. Psychological Bulletin, 130(4), 553-573.

Bateman, A. W., \& Fonagy, P. (2004). Mentalization-based treatment of BPD. Journal of Personality Disorders, 18(1), 36-51.

Beauregard, M. (2007). Mind does really matter: Evidence from neuroimaging studies of emotional self-regulation, psychotherapy, and placebo effect. Progress in Neurobiology, 81(4), 218-236.

Beauregard, M., Levesque, J., \& Bourgouin, P. (2001). Neural correlates of conscious self-regulation of emotion. The Journal of Neuroscience: The Official Journal of the Society for Neuroscience, 21(18), RC165.

Bechara, A. (2004). The role of emotion in decision-making: Evidence from neurological patients with orbitofrontal damage. Brain and Cognition, 55(1), 30-40.

Bechara, A., Damasio, A. R., Damasio, H., \& Anderson, S. W. (1994). Insensitivity to future consequences following damage to human prefrontal cortex. Cognition, 50(1), 7-15.

Bechara, A., Damasio, H., \& Damasio, A. R. (2000). Emotion, decision making and the orbitofrontal cortex. Cerebral Cortex (New York, NY: 1991), 10(3), 295-307.

Bechara, A., Damasio, H., Tranel, D., \& Anderson, S. W. (1998). Dissociation of working memory from decision making within the human prefrontal cortex. The Journal of Neuroscience: The Official Journal of the Society for Neuroscience, 18(1), 428-437.

Beck, A. T. (1976). Cognitive therapy and the emotional disorders. New York, NY: International University Press.

Beck, A. T. (2008). The evolution of the cognitive model of depression and its neurobiological correlates. American Journal of Psychiatry, 165(8), 969-977.

Beck, A. T., Rush, A. J., Shaw, B. F., \& Emery, G. (1979). Cognitive therapy of depression. New York, NY: Guildford Press. 
Beevers, C., \& Meyer, B. (2004). Thought suppression and depression risk (Brief report). Cognition and Emotion, 18(6), 859-867.

Benelli, E., Mergenthaler, E., Walter, S., Messina, I., Sambin, M., Buchheim, A., ... Viviani, R. (2012). Emotional and cognitive processing of narratives and individual appraisal styles: Recruitment of cognitive control networks vs. modulation of deactivations. Frontiers in Human Neuroscience, 6, 239.

Berking, M., \& Wupperman, P. (2012). Emotion regulation and mental health: Recent findings, current challenges, and future directions. Current Opinion in Psychiatry, 25(2), 128-134.

Berking, M., Wupperman, P., Reichardt, A., Pejic, T., Dippel, A., \& Znoj, H. (2008). Emotion-regulation skills as a treatment target in psychotherapy. Behaviour Research and Therapy, 46(11), 1230-1237.

Beutel, M. E., Stark, R., Pan, H., Silbersweig, D., \& Dietrich, S. (2010). Changes of brain activation pre- post short-term psychodynamic inpatient psychotherapy: An fMRI study of panic disorder patients. Psychiatry Research, 184(2), 96-104.

Binder, J., Medler, D. A., Desai, R., Conant, L., \& Liebenthal, E. (2005). Some neurophysiological constraints on models of word naming. NeuroImage, 27(3), 677-693.

Binder, J. R., Desai, R. H., Graves, W. W., \& Conant, L. L. (2009). Where is the semantic system? A critical review and meta-analysis of 120 functional neuroimaging studies. Cerebral Cortex, 19(12), 2767-2796.

Bishop, S., Duncan, J., Brett, M., \& Lawrence, A. D. (2004a). Prefrontal cortical function and anxiety: Controlling attention to threat-related stimuli. Nature Neuroscience, 7(2), 184-188.

Bishop, S., Duncan, J., Brett, M., \& Lawrence, A. D. (2004b). Prefrontal cortical function and anxiety: Controlling attention to threat-related stimuli. Nature Neuroscience, 7(2), 184-188.

Bishop, S. J., Jenkins, R., \& Lawrence, A. D. (2007). Neural processing of fearful faces: Effects of anxiety are gated by perceptual capacity limitations. Cerebral Cortex (New York, NY: 1991), 17(7), 1595-1603.

Bobrow, D. G., \& Norman, D. A. (1975). Some principles of memory schemata. In D. G. Bobrow \& A. G. Collins (Eds.), Representation and understanding: Studies in cognitive science (pp.131-50). New York: Academic Press.

Buchheim, A., Viviani, R., Kessler, H., Kachele, H., Cierpka, M., Roth, G., ... Taubner, S. (2012). Changes in prefrontal-limbic function in major depression after 15 months of long-term psychotherapy. PLOS ONE, 7(3), e33745.

Buhle, J. T., Silvers, J. A., Wager, T. D., Lopez, R., Onyemekwu, C., Kober, H., . . Ochsner, K. N. (2014). Cognitive reappraisal of emotion: A meta-analysis of human neuroimaging studies. Cerebral Cortex (New York, NY: 1991), 24(11), 2981-2990.

Cohen, N., Daches, S., Mor, N., \& Henik, A. (2014). Inhibition of negative content $-\mathrm{A}$ shared process in rumination and reappraisal. Frontiers in Psychology, 5, 622.

Cole, P. M., Michel, M. K., \& Teti, L. O. (1994). The development of emotion regulation and dysregulation: A clinical perspective. Monographs of the Society for Research in Child Development, $59(2 / 3), 73-102$.

Compton, R. J. (2003). The interface between emotion and attention: A review of evidence from psychology and neuroscience. Behavioral and Cognitive Neuroscience Reviews, 2(2), 115-129.

Compton, R. J., Banich, M. T., Mohanty, A., Milham, M. P., Herrington, J., Miller, G. A., . . Heller, W. (2003). Paying attention to emotion. Cognitive, Affective, \& Behavioral Neuroscience, 3(2), 81-96.

Corbetta, M., Patel, G., \& Shulman, G. L. (2008). The reorienting system of the human brain: From environment to theory of mind. Neuron, 58(3), 306-324.

Cowan, N. (1988). Evolving conceptions of memory storage, selective attention, and their mutual constraints within the human information-processing system. Psychological Bulletin, 104(2), 163.

Cramer, P. (1999). Personality, personality disorders, and defense mechanisms. Journal of Personality, 67(3), 535-554.
Dalgleish, T., Yiend, J., Schweizer, S., \& Dunn, B. D. (2009). Ironic effects of emotion suppression when recounting distressing memories. Emotion, 9(5), 744

De Gelder, B. (2006). Towards the neurobiology of emotional body language. Nature Reviews Neuroscience, 7(3), 242-249.

DeRubeis, R. J., Siegle, G. J., \& Hollon, S. D. (2008). Cognitive therapy versus medication for depression: Treatment outcomes and neural mechanisms. Nature Reviews Neuroscience, 9(10), 788-796.

Desimone, R., \& Duncan, J. (1995). Neural mechanisms of selective visual attention. Annual Review of Neuroscience, 18(1), 193-222.

D'Esposito, M., \& Postle, B. R. (2015). The cognitive neuroscience of working memory. Annual Review of Psychology, 66, 115-142.

Dichter, G. S., Felder, J. N., \& Smoski, M. J. (2010). The effects of brief behavioral activation therapy for depression on cognitive control in affective contexts: An fMRI investigation. Journal of Affective Disorders, 126(1/2), 236-244.

Diekhof, E. K., Geier, K., Falkai, P., \& Gruber, O. (2011). Fear is only as deep as the mind allows: A coordinate-based meta-analysis of neuroimaging studies on the regulation of negative affect. NeuroImage, $58(1), 275-285$.

Disner, S. G., Beevers, C. G., Haigh, E. A., \& Beck, A. T. (2011). Neural mechanisms of the cognitive model of depression. Nature Reviews Neuroscience, 12(8), 467-477.

Drevets, W. C., \& Raichle, M. E. (1998). Reciprocal suppression of regional cerebral blood flow during emotional versus higher cognitive processes: Implications for interactions between emotion and cognition. Cognition and Emotion, 12(3), 353-385.

Duncan, J., \& Owen, A. M. (2000). Common regions of the human frontal lobe recruited by diverse cognitive demands. Trends in Neurosciences, 23(10), 475-483.

Ellis, A. (1989). Rational-emotive therapy. Itasca, IL: F. E. Peacock.

Etchegoyen, R. H. (2005). The fundamentals of psychoanalytic technique. London, UK: Karnac Books.

Etkin, A., Egner, T., \& Kalisch, R. (2011). Emotional processing in anterior cingulate and medial prefrontal cortex. Trends in Cognitive Sciences, 15(2), 85-93.

Etkin, A., \& Wager, T. D. (2007). Functional neuroimaging of anxiety: A meta-analysis of emotional processing in PTSD, social anxiety disorder, and specific phobia. American Journal of Psychiatry, 164(10), 1476-1488.

Fairhall, S. L., \& Caramazza, A. (2013). Brain regions that represent amodal conceptual knowledge. The Journal of Neuroscience: The Official Journal of the Society for Neuroscience, 33(25), 10552-10558.

Falquez, R., Couto, B., Ibanez, A., Freitag, M. T., Berger, M., Arens, E. A.,... Barnow, S. (2014). Detaching from the negative by reappraisal: The role of right superior frontal gyrus (BA9/32). Frontiers in Behavioral Neuroscience, 8, 165.

Freud, S. (1926). Inhibitions, symptoms, and anxiety. Standard Edition, 20, 77-175.

Frewen, P. A., Dozois, D. J., \& Lanius, R. A. (2008). Neuroimaging studies of psychological interventions for mood and anxiety disorders: Empirical and methodological review. Clinical Psychology Review, 28(2), 228-246.

Friedman, N. P., \& Miyake, A. (2004). The relations among inhibition and interference control functions: A latent-variable analysis. Journal of Experimental Psychology: General, 113, 101-135.

Fu, C. H., Williams, S. C., Cleare, A. J., Scott, J., Mitterschiffthaler, M. T., Walsh, N. D., ... Murray, R. M. (2008). Neural responses to sad facial expressions in major depression following cognitive behavioral therapy. Biological Psychiatry, 64(6), 505-512.

Giuliani, N. R., Drabant, E. M., \& Gross, J. J. (2011). Anterior cingulate cortex volume and emotion regulation: Is bigger better? Biological Psychology, 86(3), 379-382.

Goldapple, K., Segal, Z., Garson, C., Lau, M., Bieling, P., Kennedy, S., \& Mayberg, H. (2004). Modulation of cortical-limbic pathways in 
major depression: Treatment-specific effects of cognitive behavior therapy. Archives of General Psychiatry, 61(1), 34-41.

Goldin, P. R., Ziv, M., Jazaieri, H., Hahn, K., Heimberg, R., \& Gross, J. J. (2013). Impact of cognitive behavioral therapy for social anxiety disorder on the neural dynamics of cognitive reappraisal of negative self-beliefs: Randomized clinical trial. JAMA Psychiatry, 70(10), 1048-1056.

Goldin, P. R., McRae, K., Ramel, W., \& Gross, J. J. (2008). The neural bases of emotion regulation: Reappraisal and suppression of negative emotion. Biological Psychiatry, 63(6), 577-586.

Gottfried, J. A., \& Zelano, C. (2011). The value of identity: Olfactory notes on orbitofrontal cortex function. Annals of the New York Academy of Sciences, 1239(1), 138-148.

Graham, B. M., \& Milad, M. R. (2011). The study of fear extinction: Implications for anxiety disorders. American Journal of Psychiatry, 168(12), 1255-1265.

Greenberg, L. S., \& Pascual-Leone, A. (2006). Emotion in psychotherapy: A practice-friendly research review. Journal of Clinical Psychology, 62(5), 611-630.

Grimm, S., Boesiger, P., Beck, J., Schuepbach, D., Bermpohl, F., Walter, M., ... Northoff, G. (2009). Altered negative BOLD responses in the default-mode network during emotion processing in depressed subjects. Neuropsychopharmacology: Official Publication of the American College of Neuropsychopharmacology, 34(4), 932-843.

Grimm, S., Ernst, J., Boesiger, P., Schuepbach, D., Boeker, H., \& Northoff, G. (2011). Reduced negative BOLD responses in the default-mode network and increased self-focus in depression. The World Journal of Biological Psychiatry, 12(8), 627-637.

Gross, J. J. (1998). The emerging field of emotion regulation: An integrative review. Review of General Psychology, 2(3), 271-299.

Gross, J. J. (1999). Emotion regulation: Past, present, future. Cognition \& Emotion, 13(5), 551-573.

Gross, J. J. (2002). Emotion regulation: Affective, cognitive, and social consequences. Psychophysiology, 39(3), 281-291.

Gross, J. J., \& John, O. P. (2003). Individual differences in two emotion regulation processes: Implications for affect, relationships, and wellbeing. Journal of Personality and Social Psychology, 85(2), 348-362.

Gyurak, A., Gross, J. J., \& Etkin, A. (2011). Explicit and implicit emotion regulation: A dual-process framework. Cognition and Emotion, 25(3), 400-412.

Hare, T. A., Camerer, C. F., \& Rangel, A. (2009). Self-control in decisionmaking involves modulation of the vmPFC valuation system. Science (New York, NY), 324(5927), 646-648.

Hariri, A. R., Bookheimer, S. Y., \& Mazziotta, J. C. (2000). Modulating emotional responses: Effects of a neocortical network on the limbic system. Neuroreport, 11(1), 43-48.

Hasher, L., Lustig, C., \& Zacks, R. (2007). Inhibitory mechanisms and the control of attention. Variation in Working Memory, 19, 227-249.

Hauner, K. K., Mineka, S., Voss, J. L., \& Paller, K. A. (2012). Exposure therapy triggers lasting reorganization of neural fear processing. Proceedings of the National Academy of Sciences of the United States of America, 109(23), 9203-9208.

Hayes, J. P., Morey, R. A., Petty, C. M., Seth, S., Smoski, M. J., McCarthy, G., \& Labar, K. S. (2010). Staying cool when things get hot: Emotion regulation modulates neural mechanisms of memory encoding. Frontiers in Human Neuroscience, 4, 230.

Hodges, J. R., \& Patterson, K. (1995). Is semantic memory consistently impaired early in the course of Alzheimer's disease? Neuroanatomical and diagnostic implications. Neuropsychologia, 33(4), 441-459.

Hofmann, W., Schmeichel, B. J., \& Baddeley, A. D. (2012). Executive functions and self-regulation. Trends in Cognitive Sciences, 16(3), 174-180.

Hopfinger, J. B., Buonocore, M. H., \& Mangun, G. R. (2000). The neural mechanisms of top-down attentional control. Nature Neuroscience, 3(3), 284-291.

Horowitz, M. J. (1994). States, schemas, and control: General theories for psychotherapy integration. Clinical Psychology \& Psychotherapy, 1(3), 143-152.
Horowitz, M. J. (1997). Cognitive psychodynamics: The clinical use of states, person schemas, and defensive control process theories. Cognitive Science and the Unconscious, , 189-205.

Howard, J. D., Gottfried, J. A., Tobler, P. N., \& Kahnt, T. (2015). Identityspecific coding of future rewards in the human orbitofrontal cortex. Proceedings of the National Academy of Sciences of the United States of America, 112(16), 5195-5200.

Hu, T., Zhang, D., Wang, J., Mistry, R., Ran, G., \& Wang, X. (2014). Relation between emotion regulation and mental health: A metaanalysis review. Psychological Reports, 114(2), 341-362.

Irish, M., Hodges, J. R., \& Piguet, O. (2014). Right anterior temporal lobe dysfunction underlies theory of mind impairments in semantic dementia. Brain: A Journal of Neurology, 137(Pt. 4), 1241-1253.

James, I. A., Southam, L., \& Blackburn, I. M. (2004). Schemas revisited. Clinical Psychology \& Psychotherapy, 11(6), 369-377.

Jefferies, E. (2013). The neural basis of semantic cognition: Converging evidence from neuropsychology, neuroimaging and TMS. Cortex, 49(3), 611-625.

Johnstone, T., van Reekum, C. M., Urry, H. L., Kalin, N. H., \& Davidson, R. J. (2007). Failure to regulate: Counterproductive recruitment of top-down prefrontal-subcortical circuitry in major depression. The Journal of Neuroscience: The Official Journal of the Society for Neuroscience, 27(33), 8877-8884.

Joormann, J., \& Gotlib, I. H. (2010). Emotion regulation in depression: Relation to cognitive inhibition. Cognition \& Emotion, 24(2), 281-298.

Joormann, J., Levens, S. M., \& Gotlib, I. H. (2011). Sticky thoughts: Depression and rumination are associated with difficulties manipulating emotional material in working memory. Psychological Science, 22(8), 979-983.

Kabat-Zinn, J. (2003). Mindfulness-based interventions in context: Past, present, and future. Clinical Psychology: Science and Practice, $10(2), 144-156$.

Kable, J. W., \& Glimcher, P. W. (2007). The neural correlates of subjective value during intertemporal choice. Nature Neuroscience, 10(12), 1625-1633.

Kable, J. W., \& Glimcher, P. W. (2009). The neurobiology of decision: Consensus and controversy. Neuron, 63(6), 733-745.

Kalisch, R. (2009). The functional neuroanatomy of reappraisal: Time matters. Neuroscience \& Biobehavioral Reviews, 33(8), 1215-1226.

Kalisch, R., Wiech, K., Critchley, H. D., \& Dolan, R. J. (2006). Levels of appraisal: A medial prefrontal role in high-level appraisal of emotional material. NeuroImage, 30(4), 1458-1466.

Kalisch, R., Wiech, K., Herrmann, K., \& Dolan, R. J. (2006). Neural correlates of self-distraction from anxiety and a process model of cognitive emotion regulation. Journal of Cognitive Neuroscience, 18(8), 1266-1276

Kanske, P., Heissler, J., Schonfelder, S., Bongers, A., \& Wessa, M. (2011). How to regulate emotion? neural networks for reappraisal and distraction. Cerebral Cortex (New York, NY: 1991), 21(6), 1379-1388.

Kennedy, S. H., Konarski, J. Z., Segal, Z. V., Lau, M. A., Bieling, P. J., McIntyre, R. S., \& Mayberg, H. S. (2007). Differences in brain glucose metabolism between responders to $\mathrm{CBT}$ and venlafaxine in a 16-week randomized controlled trial. The American Journal of Psychiatry, 164(5), 778-788.

Koenigsberg, H. W., Fan, J., Ochsner, K. N., Liu, X., Guise, K., Pizzarello, S., . . Siever, L. J. (2010). Neural correlates of using distancing to regulate emotional responses to social situations. Neuropsychologia, 48(6), 1813-1822.

Kohn, N., Eickhoff, S., Scheller, M., Laird, A., Fox, P., \& Habel, U. (2014). Neural network of cognitive emotion regulation-An ALE meta-analysis and MACM analysis. NeuroImage, 87, 345-355.

Koole, S. L., \& Coenen, L. H. M. (2007). Implicit self and affect regulation: Effects of action orientation and subliminal self priming in an affective priming task. Self and Identity, 6, 118-136. 
Koole, S. L., \& Rothermund, K. (2011). "I feel better but I don't know why": The psychology of implicit emotion regulation. Cognition \& Emotion, 25(3), 389-399.

Kosson, D., Budhani, S., Nakic, M., Chen, G., Saad, Z., Vythilingam, M., ... Blair, R. (2006). The role of the amygdala and rostral anterior cingulate in encoding expected outcomes during learning. NeuroImage, 29(4), 1161-1172.

Lang, P., \& Bradley, M. M. (2007). The international affective picture system (IAPS) in the study of emotion and attention. Handbook of Emotion Elicitation and Assessment, 29, 29-46.

Leichsenring, F., \& Rabung, S. (2011). Long-term psychodynamic psychotherapy in complex mental disorders: Update of a meta-analysis. The British Journal of Psychiatry: The Journal of Mental Science, 199(1), 15-22.

Lieberman, M. D., Eisenberger, N. I., Crockett, M. J., Tom, S. M., Pfeifer, J. H., \& Way, B. M. (2007). Putting feelings into words: Affect labeling disrupts amygdala activity in response to affective stimuli. Psychological Science, 18(5), 421-428.

Liljeholm, M., Tricomi, E., O’Doherty, J. P., \& Balleine, B. W. (2011). Neural correlates of instrumental contingency learning: Differential effects of action-reward conjunction and disjunction. The Journal of Neuroscience: The Official Journal of the Society for Neuroscience, 31(7), 2474-2480

Lindauer, R. J., Booij, J., Habraken, J. B., van Meijel, E. P., Uylings, H. B., Olff, M., ... Gersons, B. P. (2008). Effects of psychotherapy on regional cerebral blood flow during trauma imagery in patients with post-traumatic stress disorder: A randomized clinical trial. Psychological Medicine, 38(4), 543-554.

Lindquist, K. A., Wager, T. D., Kober, H., Bliss-Moreau, E., \& Barrett, L. F. (2012). The brain basis of emotion: A meta-analytic review. Behavioral and Brain Sciences, 35(03), 121-143.

Lipsey, M. W., \& Wilson, D. B. (1993). The efficacy of psychological, educational, and behavioral treatment. confirmation from meta-analysis. The American Psychologist, 48(12), 1181-1209.

Logan, G. D. (1988). Toward an instance theory of automatization. Psychological Review, 95(4), 492.

Lou, H. C., Luber, B., Crupain, M., Keenan, J. P., Nowak, M., Kjaer, T. W., ... Lisanby, S. H. (2004). Parietal cortex and representation of the mental self. Proceedings of the National Academy of Sciences of the United States of America, 101(17), 6827-6832.

Luo, Q., Mitchell, D., Jones, M., Mondillo, K., Vythilingam, M., \& Blair, R. J. R. (2007). Common regions of dorsal anterior cingulate and prefrontal-parietal cortices provide attentional control of distracters varying in emotionality and visibility. NeuroImage, 38(3), 631-639.

Mauss, I. B., Bunge, S. A., \& Gross, J. J. (2007). Automatic emotion regulation. Social and Personality Psychology Compass, 1, 1-18.

McClure, S. M., Laibson, D. I., Loewenstein, G., \& Cohen, J. D. (2004). Separate neural systems value immediate and delayed monetary rewards. Science (New York, NY), 306(5695), 503-507.

McElree, B. (1998). Attended and non-attended states in working memory: Accessing categorized structures. Journal of Memory and Language, 38(2), 225-252.

McGinn, L. K., \& Young, J. E. (1996). Schema-focused therapy. In P. Salkovskis (Ed.), Frontiers of Cognitive Therapy (pp. 182-207). New York, NY: Guilford Press.

McRae, K., Hughes, B., Chopra, S., Gabrieli, J. D., Gross, J. J., \& Ochsner, K. N. (2010). The neural bases of distraction and reappraisal. Journal of Cognitive Neuroscience, 22(2), 248-262.

Messina, I., Bianco, S., Sambin, M., \& Viviani, R. (2015). Executive and semantic processes in reappraisal of negative stimuli: Insights from a meta-analysis of neuroimaging studies. Frontiers in Psychology, 6, 956.

Messina, I., Sambin, M., Palmieri, A., \& Viviani, R. (2013). Neural correlates of psychotherapy in anxiety and depression: A meta-analysis. PLOS ONE, 8(9), e 74657.

Mesulam, M. (1998). From sensation to cognition. Brain, 121(6), 1013-1052.
Milad, M. R., \& Quirk, G. J. (2012). Fear extinction as a model for translational neuroscience: Ten years of progress. Annual Review of Psychology, 63, 129-151.

Morrison, S. E., \& Salzman, C. D. (2010). Re-valuing the amygdala. Current Opinion in Neurobiology, 20(2), 221-230.

Murray, E. A. (2007). The amygdala, reward and emotion. Trends in Cognitive Sciences, 11(11), 489-497.

Nolen-Hoeksema, S. (2000). The role of rumination in depressive disorders and mixed anxiety/depressive symptoms. Journal of Abnormal Psychology, 109(3), 504-511.

Noonan, M., Kolling, N., Walton, M., \& Rushworth, M. (2012). Reevaluating the role of the orbitofrontal cortex in reward and reinforcement. European Journal of Neuroscience, 35(7), 997-1010.

Northoff, G., Heinzel, A., Bermpohl, F., Niese, R., Pfennig, A., PascualLeone, A., \& Schlaug, G. (2004). Reciprocal modulation and attenuation in the prefrontal cortex: An fMRI study on emotional-cognitive interaction. Human Brain Mapping, 21(3), 202-212.

Oberauer, K. (2009). Design for a working memory. Psychology of Learning and Motivation, 51, 45-100.

Ochsner, K. N., Bunge, S. A., Gross, J. J., \& Gabrieli, J. D. (2002). Rethinking feelings: An FMRI study of the cognitive regulation of emotion. Journal of Cognitive Neuroscience, 14(8), 1215-1229.

Ochsner, K. N., \& Gross, J. J. (2005). The cognitive control of emotion. Trends in Cognitive Sciences, 9(5), 242-249.

Ochsner, K. N., \& Gross, J. J. (2008). Cognitive emotion regulation: Insight from social cognitive and affective neuroscience. Current Directions in Psychological Science, 17(2), 153-158.

Ohira, H., Nomura, M., Ichikawa, N., Isowa, T., Iidaka, T., Sato, A., . . . Yamada, J. (2006). Association of neural and physiological responses during voluntary emotion suppression. NeuroImage, 29(3), 721-733.

Owen, A. M., McMillan, K. M., Laird, A. R., \& Bullmore, E. (2005). N-back working memory paradigm: A meta-analysis of normative functional neuroimaging studies. Human Brain Mapping, 25(1), 46-59.

Paquette, V., Levesque, J., Mensour, B., Leroux, J. M., Beaudoin, G., Bourgouin, P., \& Beauregard, M. (2003). "Change the mind and you change the brain": Effects of cognitive-behavioral therapy on the neural correlates of spider phobia. NeuroImage, 18(2), 401-409.

Parkes, S. L., Bradfield, L. A., \& Balleine, B. W. (2015). Interaction of insular cortex and ventral striatum mediates the effect of incentive memory on choice between goal-directed actions. The Journal of Neuroscience: The Official Journal of the Society for Neuroscience, 35(16), 6464-6471.

Patterson, K., Nestor, P. J., \& Rogers, T. T. (2007). Where do you know what you know? the representation of semantic knowledge in the human brain. Nature Reviews Neuroscience, 8(12), 976-987.

Peelen, M. V., Atkinson, A. P., \& Vuilleumier, P. (2010). Supramodal representations of perceived emotions in the human brain. The Journal of Neuroscience: The Official Journal of the Society for Neuroscience, 30(30), 10127-10134.

Pessoa, L., McKenna, M., Gutierrez, E., \& Ungerleider, L. G. (2002). Neural processing of emotional faces requires attention. Proceedings of the National Academy of Sciences of the United States of America, 99(17), 11458-11463.

Phan, K. L., Fitzgerald, D. A., Nathan, P. J., Moore, G. J., Uhde, T. W., \& Tancer, M. E. (2005). Neural substrates for voluntary suppression of negative affect: A functional magnetic resonance imaging study. Biological Psychiatry, 57(3), 210-219.

Phelps, E. A., Delgado, M. R., Nearing, K. I., \& LeDoux, J. E. (2004). Extinction learning in humans: Role of the amygdala and vmPFC. Neuron, 43(6), 897-905.

Phillips, M. L., Drevets, W. C., Rauch, S. L., \& Lane, R. (2003). Neurobiology of emotion perception: I. The neural basis of normal emotion perception. Biological Psychiatry, 54(5), 504-514.

Posner, M. I., \& Rothbart, M. K. (2007). Research on attention networks as a model for the integration of psychological science. Annual Review of Psychology, 58, 1-23. 
Posner, M. I., Rothbart, M. K., Vizueta, N., Thomas, K. M., Levy, K. N., Fossella, J., . . . Kernberg, O. (2003). An approach to the psychobiology of personality disorders. Development and Psychopathology, 15(4), 1093-1106.

Postman, L., \& Underwood, B. J. (1973). Critical issues in interference theory. Memory \& Cognition, 1(1), 19-40.

Raichle, M. E., Fiez, J. A., Videen, T. O., MacLeod, A. M., Pardo, J. V., Fox, P. T., \& Petersen, S. E. (1994). Practice-related changes in human brain functional anatomy during nonmotor learning. Cerebral Cortex (New York, NY: 1991), 4(1), 8-26.

Raichle, M. E., MacLeod, A. M., Snyder, A. Z., Powers, W. J., Gusnard, D. A., \& Shulman, G. L. (2001). A default mode of brain function. Proceedings of the National Academy of Sciences of the United States of America, 98(2), 676-682.

Rangel, A., Camerer, C., \& Montague, P. R. (2008). A framework for studying the neurobiology of value-based decision making. Nature Reviews Neuroscience, 9(7), 545-556.

Rangel, A., \& Clithero, J. (2013). The computation of stimulus values in simple choice. Neuroeconomics: Decision Making and the Brain, 2, $125-147$.

Rolls, E. T. (2000). The orbitofrontal cortex and reward. Cerebral Cortex (New York, NY: 1991), 10(3), 284-294.

Rude, S. S., Durham-Fowler, J. A., Baum, E. S., Rooney, S. B., \& Maestas, K. L. (2010). Self-report and cognitive processing measures of depressive thinking predict subsequent major depressive disorder. Cognitive Therapy and Research, 34(2), 107-115.

Rude, S. S., Valdez, C. R., Odom, S., \& Ebrahimi, A. (2003). Negative cognitive biases predict subsequent depression. Cognitive Therapy and Research, 27(4), 415-429.

Rude, S. S., Wenzlaff, R. M., Gibbs, B., Vane, J., \& Whitney, T. (2002). Negative processing biases predict subsequent depressive symptoms. Cognition and Emotion, 16(3), 423-440.

Rudebeck, P. H., Saunders, R. C., Prescott, A. T., Chau, L. S., \& Murray, E. A. (2013). Prefrontal mechanisms of behavioral flexibility, emotion regulation and value updating. Nature Neuroscience, 16(8), 1140-1145.

Rumelhart, D., \& Ortony, A. (1977). The representation of knowledge in memory. In R. C. Anderson, R. J. Spiro, \& W. E. Montague (Eds.), Schooling and the acquisition of knowledge (pp. 99-136). Hillsdale, NJ: Erlbaum.

Ryle, A. (1991). Object relations theory and activity theory: A proposed link by way of the procedural sequence model. British Journal of Medical Psychology, 64(4), 307-316.

Sakai, Y., Kumano, H., Nishikawa, M., Sakano, Y., Kaiya, H., Imabayashi, E., . . Kuboki, T. (2006). Changes in cerebral glucose utilization in patients with panic disorder treated with cognitivebehavioral therapy. NeuroImage, 33(1), 218-226.

Saxe, R. (2006). Uniquely human social cognition. Current Opinion in Neurobiology, 16(2), 235-239.

Schienle, A., Schafer, A., Hermann, A., Rohrmann, S., \& Vaitl, D. (2007). Symptom provocation and reduction in patients suffering from spider phobia: An fMRI study on exposure therapy. European Archives of Psychiatry and Clinical Neuroscience, 257(8), 486-493.

Schnell, K., \& Herpertz, S. C. (2007). Effects of dialectic-behavioral-therapy on the neural correlates of affective hyperarousal in borderline personality disorder. Journal of Psychiatric Research, 41(10), 837-847.

Schoenbaum, G., Roesch, M. R., Stalnaker, T. A., \& Takahashi, Y. K. (2009). A new perspective on the role of the orbitofrontal cortex in adaptive behaviour. Nature Reviews Neuroscience, 10(12), 885-892.

Schoenbaum, G., Setlow, B., Saddoris, M. P., \& Gallagher, M. (2003). Encoding predicted outcome and acquired value in orbitofrontal cortex during cue sampling depends upon input from basolateral amygdala. Neuron, 39(5), 855-867.

Segal, Z. V., Williams, J. M. G., \& Teasdale, J. D. (2012). Mindfulness-based cognitive therapy for depression. New York, NY: Guilford Press.

Seymour, B., \& Dolan, R. (2008). Emotion, decision making, and the amygdala. Neuron, 58(5), 662-671.
Shipherd, J. C., \& Beck, J. G. (2005). The role of thought suppression in posttraumatic stress disorder. Behavior Therapy, 36(3), 277-287.

Shulman, G. L., Fiez, J. A., Corbetta, M., Buckner, R. L., Miezin, F. M., Raichle, M. E., \& Petersen, S. E. (1997). Common blood flow changes across visual tasks: II. Decreases in cerebral cortex. Journal of Cognitive Neuroscience, 9(5), 648-663.

Siegle, G. J., Thompson, W., Carter, C. S., Steinhauer, S. R., \& Thase, M. E. (2007). Increased amygdala and decreased dorsolateral prefrontal BOLD responses in unipolar depression: Related and independent features. Biological Psychiatry, 61(2), 198-209.

Small, D. M., Zatorre, R. J., Dagher, A., Evans, A. C., \& Jones-Gotman, M. (2001). Changes in brain activity related to eating chocolate: From pleasure to aversion. Brain: A Journal of Neurology, 124(Pt. 9), 1720-1733.

Smith, M. L., \& Glass, G. V. (1977). Meta-analysis of psychotherapy outcome studies. The American Psychologist, 32(9), 752-760.

Sperduti, M., Martinelli, P., Kalenzaga, S., Devauchelle, A., Lion, S., Malherbe, C., . . . Oppenheim, C. (2013). Don't be too strict with yourself! Rigid negative self-representation in healthy subjects mimics the neurocognitive profile of depression for autobiographical memory. Frontiers in Behavioral Neuroscience, 7, 41.

Straube, T., Glauer, M., Dilger, S., Mentzel, H., \& Miltner, W. H. R. (2006). Effects of cognitive-behavioural therapy on brain activation in specific phobia. NeuroImage, 29(1), 125-135.

Taylor, S. F., \& Liberzon, I. (2007). Neural correlates of emotion regulation in psychopathology. Trends in Cognitive Sciences, 11(10), 413-418.

Thomaes, K., Dorrepaal, E., Draijer, N., Jansma, E. P., Veltman, D. J., \& van Balkom, A. J. (2014). Can pharmacological and psychological treatment change brain structure and function in PTSD? A systematic review. Journal of Psychiatric Research, 50, 1-15.

Thompson, R. A. (1994). Emotion regulation: A theme in search of definition. Monographs of the Society for Research in Child Development, 59(2-3), 25-52.

Tranel, D., Damasio, H., \& Damasio, A. R. (1997). A neural basis for the retrieval of conceptual knowledge. Neuropsychologia, 35(10), $1319-1327$.

Tulving, E. (1972). Episodic and semantic memory 1. Organization of Memory. London: Academic, 381(e402), 4.

Vanderhasselt, M. A., Baeken, C., Van Schuerbeek, P., Luypaert, R., \& De Raedt, R. (2012). Inter-individual differences in the habitual use of cognitive reappraisal and expressive suppression are associated with variations in prefrontal cognitive control for emotional information: An event related fMRI study. Biological Psychology, 92(3), 433-439.

Visser, M., Jefferies, E., \& Ralph, M. L. (2010). Semantic processing in the anterior temporal lobes: A meta-analysis of the functional neuroimaging literature. Journal of Cognitive Neuroscience, 22(6), 1083-1094.

Viviani, R. (2013). Emotion regulation, attention to emotion, and the ventral attentional network. Frontiers in Human Neuroscience, 7 , 746.

Viviani, R. (2014). Neural correlates of emotion regulation in the ventral prefrontal cortex and the encoding of subjective value and economic utility. Frontiers in Psychiatry, 5

Viviani, R., Lo, H., Sim, E., Beschoner, P., Stingl, J. C., \& Horn, A. B. (2010). The neural substrate of positive bias in spontaneous emotional processing. PLOS ONE, 5(11), e15454.

Vocks, S., Busch, M., Schulte, D., Gronermeyer, D., Herpertz, S., \& Suchan, B. (2010). Effects of body image therapy on the activation of the extrastriate body area in anorexia nervosa: An fMRI study. Psychiatry Research, 183(2), 114-118.

Vocks, S., Schulte, D., Busch, M., Grönemeyer, D., Herpertz, S., \& Suchan, B. (2011). Changes in neuronal correlates of body image processing by means of cognitive-behavioural body image therapy for eating disorders: A randomized controlled fMRI study. Psychological Medicine, 41(08), 1651-1663. 
Vrticka, P., Sander, D., \& Vuilleumier, P. (2011). Effects of emotion regulation strategy on brain responses to the valence and social content of visual scenes. Neuropsychologia, 49(5), 1067-1082.

Wager, T. D., Davidson, M. L., Hughes, B. L., Lindquist, M. A., \& Ochsner, K. N. (2008). Prefrontal-subcortical pathways mediating successful emotion regulation. Neuron, 59(6), 1037-1050.

Wegner, D. M. (1994). Ironic processes of mental control. Psychological Review, 101(1), 34-52.

Wegner, D. M., Erber, R., \& Zanakos, S. (1993). Ironic processes in the mental control of mood and mood-related thought. Journal of Personality and Social Psychology, 65(6), 1093.

Wells, A. (2011). Metacognitive therapy for anxiety and depression. New York, NY: Guilford Press.

Wenzlaff, R. (1991). Causal attributions of depression. Annual Review of Psychology, 51, 59-91.

Wenzlaff, R. M., \& Rude, S. S. (2002). Cognitive vulnerability to depression: The role of thought suppression and attitude certainty. Cognition \& Emotion, 16(4), 533-548.

Wenzlaff, R. M., Rude, S. S., Taylor, C. J., Stultz, C. H., \& Sweatt, R. A. (2001). Beneath the veil of thought suppression: Attentional bias and depression risk. Cognition \& Emotion, 15(4), 435-452.

Wenzlaff, R. M., \& Wegner, D. M. (2000). Thought suppression. Annual Review of Psychology, 51, 59-91.

Wenzlaff, R. M., Wegner, D. M., \& Roper, D. W. (1988). Depression and mental control: The resurgence of unwanted negative thoughts. Journal of Personality and Social Psychology, 55(6), 882-892.
Westen, D., \& Morrison, K. (2001). A multidimensional metaanalysis of treatments for depression, panic, and generalized anxiety disorder: An empirical examination of the status of empirically supported therapies. Journal of Consulting and Clinical Psychology, 69(6), 875-899.

Whalen, P. J., Bush, G., McNally, R. J., Wilhelm, S., McInerney, S. C., Jenike, M. A., \& Rauch, S. L. (1998). The emotional counting Stroop paradigm: A functional magnetic resonance imaging probe of the anterior cingulate affective division. Biological Psychiatry, 44(12), 1219-1228.

Wilson, R. C., Takahashi, Y. K., Schoenbaum, G., \& Niv, Y. (2014). Orbitofrontal cortex as a cognitive map of task space. Neuron, 81(2), 267-279.

Yarkoni, T., Poldrack, R. A., Nichols, T. E., Van Essen, D. C., \& Wager, T. D. (2011). Large-scale automated synthesis of human functional neuroimaging data. Nature Methods, 8(8), 665-670.

Young, J. E. (1994). Cognitive therapy for personality disorders: A schema-focused approach. Sarasota, FL: Professional Resource Press/Professional Resource Exchange.

Young, J. E., Klosko, J. S., \& Weishaar, M. E. (2003). Schema therapy: A practitioner's guide. New York, NY: Guilford Press.

Zahn, R., Moll, J., Krueger, F., Huey, E. D., Garrido, G., \& Grafman, J. (2007). Social concepts are represented in the superior anterior temporal cortex. Proceedings of the National Academy of Sciences of the United States of America, 104(15), 6430-6435. 